\title{
PROPAGAÇÃO IN VITRO DO PORTA-ENXERTO ROSA 'SHAFTER' $\left({ }^{1}\right)$
}

\author{
ANTONIO FERNANDO CAETANO TOMBOLATO $\left({ }^{2,4}\right)$, EIDINETE APARECIDA QUIRINO $\left({ }^{4,5}\right)$, \\ SANDRA SUMIE GONÇALVES TAKEBAYASHI ( $\left(^{5}\right)$, CARLOS EDUARDO FERREIRA \\ DE CASTRO ( ${ }^{2}$ ), LUIZ ANTONIO FERRAZ MATTHES $\left({ }^{2}\right)$, VIRGÍNIO BOVI $\left({ }^{3}\right)$, \\ ROSANE CORREA FAGUNDES $\left({ }^{5}\right)$, MARIA APARECIDA LOPES DA COSTA $\left({ }^{5}\right)$, \\ ÉRIVAN OLINDA RIBEIRO $\left({ }^{4,5}\right)$ e CLÁUDIO VASCONCELOS $\left(^{5}\right)$
}

\begin{abstract}
RESUMO
Foram desenvolvidos, na Seçāo de Floricultura e Plantas Ornamentais, experimentos de micropropagaçăo de variedades de rosa. O porta-enxerto de Rosa 'Shafter' demonstrou ser excelente material, propagando-se fácil e rapidamente. Meristemas retirados de gemas da porçăo mediana das hastes, inoculados em meio de Pierik, com adição de $2 \mathrm{mg} / 1$ de 6-benzilaminopurina (6-BA), $20 \mathrm{~g} / \mathrm{l}$ de sacarose, $6,4 \mathrm{~g} / 1$ de ágar e os compostos orgánicos - meso-inositol (100 mg/l), ácido nicotínico $(0,5 \mathrm{mg} / \mathrm{l})$, piridoxina $\mathrm{HCl}(0,5 \mathrm{mg} / \mathrm{l})$, tiamina $\mathrm{HCl}(1 \mathrm{mg} / \mathrm{l})$, ácido fólico $(0,5 \mathrm{mg} / \mathrm{l})$, riboflavina $(0,5 \mathrm{mg} / \mathrm{l})$ e pantotenato de cálcio $(1 \mathrm{mg} / \mathrm{l})$ - apresentaram uma taxa de regeneraçăo de 1:33 em doze meses. Em uma segunda fase, em três experimentos, testaram-se diversos métodos de enraizamento, observando-se ser este possível em meio líquido, com ou sem auxina, sobre ponte de papel-filtro, ou em meio sólido, com $6,4 \mathrm{~g} / 1 \mathrm{de}$ ágar, com as auxinas ácido indolbutírico $(0,05$ $\mathrm{mg} / \mathrm{l})$ e ácido naftalenoacético $(0,1 \mathrm{mg} / \mathrm{l})$.
\end{abstract}

Termos de indexação: roseira, Rosa 'Shafter', micropropagação in vitro, porta-enxerto, enraizamento in vitro e meristema.

\section{ABSTRACT \\ MICROPROPAGATION OF ROSE VARIETIES: IN VITRO PROPAGATION OF ROOT STOCK ROSA 'SHAFTER'}

Experiments on rose micropropagation showed that the root stock Rosa 'Shafter' was an excellent material fast and easily propagated. It has taken 12 months to reach more than a thousand plantlets from a few inoculated meristems. In a first part of the experiments, the meristem culture evolution was observed in the medium Pierik added with $2 \mathrm{mg} / 16$-benzylaminopurine, $20 \mathrm{~g} / \mathrm{l}$ sucrose, $6.4 \mathrm{~g} / \mathrm{l}$ agar and the organic compounds: $100 \mathrm{mg} / \mathrm{l}$ myo-inositol, $0.5 \mathrm{mg} / \mathrm{l}$ nicotinic acid, $0.5 \mathrm{mg} / \mathrm{l}$ pyridoxine HCl, $1 \mathrm{mg} / \mathrm{l}$ thiamine $\mathrm{HCl}, 0.5 \mathrm{mg} / 1$ folic acid, $0.5 \mathrm{mg} / 1$ riboflavin, $1 \mathrm{mg} / 1 \mathrm{calcium}$ pantothenate. In a second part, three experiments were established to observe the rooting required conditions. Roots can be obtained in a liquid medium, with or without auxins, and in a solid medium, with $6.4 \mathrm{~g} / \mathrm{l}$ agar, with the auxins $0.05 \mathrm{mg} / \mathrm{l}$ indolbutiric acid and $0.1 \mathrm{mg} / \mathrm{l}$ naftaleneacetic acid.

Index terms: rose, Rosa 'Shafter', in vitro micropropagation, root-stock, in vitro rooting, meristem.

(') Recebido para publicação em 16 de agosto de 1991 e aceito em 19 de outubro de 1992.

( $\left.^{2}\right)$ Seção de Floricultura e Plantas Ornamentais, Instituto Agronômico (IAC), Caixa Postal 28, 13001-970 Campinas (SP).

$\left({ }^{3}\right)$ Estaçăo Experimental de São Roque (IAC), Caixa Postal 133, 18130-000 São Roque (SP).

$\left.{ }^{4}\right)$ Com bolsa da FAPESP.

(5) Com bolsa de pesquisa do CNPq. 


\section{INTRODUÇÃO}

O desenvolvimento de novas técnicas para uma rápida propagaçāo clonal in vitro tende a diminuir o tempo necessário para a introdução de novos cultivares, com características horticulturais melhoradas, aumentando a disponibilidade de plantas e contribuindo para o desenvolvimento da roseicultura.

A Seção de Floricultura e Plantas Ornamentais do Instituto Agronômico vem desenvolvendo um programa de pesquisa com o intuito de estabelecer técnicas de cultivo in vitro de variedades comerciais, novas seleções e porta-enxertos de roseira, de modo a propiciar a produção massal de plantas selecionadas, a obtenção de material sadio e a provisão de novos genótipos.

A roseira é tradicionalmente multiplicada por meio de semente, estaquia, mergulhia e enxertia (Decker \& Mendes, 1939). Em nosso País, é usual a propagação vegetativa, pela estaquia direta de porta-enxertos e, posteriormente, enxertos. Algumas variedades-copa possibilitam a propagação por estaquia direta, mostrando bom enraizamento e grande vigor. Outras variedades não apresentam crescimento satisfatório de raízes nas estacas. Uma desvantagem dos processos de propagação vegetativa consiste no acúmulo de vírus nas plantas, à medida que se multiplica sucessivamente, sem cuidados fitossanitários, normalmente ignorados ou negligenciados (Tombolato et al., 1988). A demanda de estacas para a produção de mudas, seja de variedade de porta-enxerto, seja de variedade-copa, é grande.

Vêm sendo utilizadas, no caso específico dos porta-enxertos para variedades de rosa de melhor qualidade agronômica, espécies e variedades de roseiras agrestes e vigorosas, cujas flores para o corte deixam muito a desejar (Lopes, 1980).

Não se identificou ainda qual o porta-enxerto mais adequado para a produção de rosas de corte, ou seja, aquele com as seguintes qualidades: maior facilidade de propagação, resistência às pragas $e$ moléstias do solo e compatibilidade com a maioria das variedades comerciais, conferindo-lhes maior vigor e longevidade.

Recomenda-se que as variedades de porta-enxerto sejam escolhidas segundo algumas características, como resistência ao calor e à seca, longevidade inferida à variedade sobre ele enxertada, tendência ao perfilhamento, resistência a nematóides, época de enxertia, crescimento contínuo ao longo do ano, facilidade de enxertia e adaptação ao transplante (Butterfield, 1950).

Certas variedades de porta-enxertos comumente empregadas, apesar de unirem qualidades para a produçāo de mudas de flores para o corte, apresentam dificuldades de enraizamento. Em função de tais problemas, apenas duas delas são utilizadas por grande numero de produtores nacionais - Rosa multiflora 'Japonica' e $R$. multiflora 'Paulista' - apresentando ambas rápido crescimento vegetativo e fácil enraizamento. Tem-se procurado um meio de otimizar a porcentagem de enraizamento com o emprego de hormônios, o que nāo só aumenta o número de raízes como também induz a produção de raízes maiores e mais vigorosas.

A cultura de meristemas in vitro tem-se mostrado bastante eficiente para promover a limpeza de vírus de inúmeras plantas, cujo processo tradicional de propagação é o vegetativo. Por conseguinte, essa cultura se apresenta como um recurso para a obtenção de elevada quantidade de matrizes de variedades-copa e porta-enxerto em curto espaço de tempo e, provavelmente, livres de vírus, para a produção de mudas de alto padrāo pelo método tradicional (Tombolato et al., 1988).

Este trabalho apresenta os resultados dos ensaios de micropropagaçāo e enraizamento in vitro com a variedade Shafter, considerada um porta-enxerto que confere boas qualidades à variedade-copa para a formação de mudas destinadas à produção de flores de corte.

A Rosa 'Shafter', também conhecida como 'Dr. Huey', e uma trepadeira resultante do cruzamento entre 'Ethel' (um seedling de 'Dorothy Perkins') e 'Gruss an Teplitz' (Gault \& Synge, 1987). 


\section{MATERIAL E METODOS}

Com estacas do porta-enxerto Rosa 'Shafter' (número de coleção: PE-17) da coleção da Estação Experimental de São Roque, realizou-se, em 16-5-89, a inoculação de meristemas. Após o desenvolvimento e perfilhamento das plântulas, a partir de meristemas, foram estabelecidos três ensaios de enraizamento.

\subsection{Cultura de meristema}

\section{Preparo do material e retirada do meristema}

Coletaram-se, em condiçōes de campo, hastes de roseira com gemas de tamanho considerado médio, de coloração verde e aspecto normal. As hastes foram cortadas em três a quatro estacas, com $5 \mathrm{~cm}$ de comprimento, aproximadamente, escolhendo-se sobretudo as gemas da porção mediana do ramo, onde atingem tamanho mais adequado para as manipulaçōes durante o preparo para a inoculação in vitro. A seguir, as hastes foram lavadas em água destilada e, subseqüentemente, em álcool $70 \%$.

Desinfestada a superfície, procedeu-se, em câmara de fluxo laminar sob lupa estereoscópica binocular, à retirada das escamas e dos primórdios foliares que envolvem o meristema. Este, com o auxilio de um bisturi, foi removido e colocado em tubos de ensaio contendo o meio de cultura. Cada explante inoculado media menos de $1,0 \mathrm{~mm}$ de comprimento.

\section{Preparo do meio de cultura e inoculações}

Para o desenvolvimento e crescimento do meristema, utilizou-se o meio de cultura de Pierik (1976), acrescentando-se $2,0 \mathrm{mg} / \mathrm{l}$ de 6-benzilaminopurina (6-BA); $20 \mathrm{~g} / 1$ de sacarose; $6,4 \mathrm{~g} / 1$ de ágar e um complexo vitamínico baseado nas vitaminas Murashige \& Skoog (1962) (MS) e STABA (Skirvin \& Chu, 1979), contendo meso-inositol (100 mg/l); ácido nicotínico $(0,5 \mathrm{mg} / \mathrm{l})$; piridoxina $\mathrm{HCl}(0,5 \mathrm{mg} / \mathrm{l})$; tiamina $\mathrm{HCl}(1 \mathrm{mg} /)$; ácido fólico $(0,5 \mathrm{mg} / \mathrm{l})$; riboflavina $(0,5 \mathrm{mg} / 1)$ e pantotenato de cálcio (1 mg/l). O $\mathrm{pH}$ foi corrigido para 5,8. Após permanecerem nesse substrato por cerca de três- -quatro meses, em ambiente de fotoperíodo de 16 horas (700 lux) e temperatura de $25 \pm 2^{\circ} \mathrm{C}$, os meristemas desenvolvidos foram transferidos para outro meio, também com base em Pierik (1976), com apenas $1 \mathrm{mg} / \mathrm{l}$ de 6-BA e vitaminas MS (mesoinositol $100 \mathrm{mg} /$; ácido nicotínico $0,5 \mathrm{mg} / \mathrm{l}$; piridoxina $\mathrm{HCl} 0,5 \mathrm{mg} / \mathrm{l}$ e tiamina $\mathrm{HCl} 1 \mathrm{mg} / \mathrm{l}$ ). Durante as avaliaçōes, descartaram-se semanalmente os meristemas necrosados e contaminados.

\subsection{Ensaios de enraizamento}

Instalaram-se três ensaios de enraizamento para observar as reaçōes das plântulas obtidas da cultura de meristemas em determinadas condições físicas e constituição química do meio. As plântulas foram colocadas para enraizar no claro, no escuro e parcialmente no escuro, com base no trabalho de Barbosa et al. (1986). Também foram testados meios de cultura líquido e sólido (com ágar), na presença e na ausência das auxinas ácido indolbutírico (AIB) e ácido naftalenoacético (ANA).

Para a averiguação do meio mais adequado para o enraizamento, em 18-7-90, instalou-se o ensaio I, em seis tratamentos cada um, com $\mathbf{4 0}$ plântulas de uma mesma variedade, Shafter (PE-17). Empregaram se três meios de formulação diferentes, conforme quadro 1 .

Com o mesmo cultivar e variando as condições ambientais, instalou-se o ensaio II, em 18-10-90. Quinze dias antes, as plântulas utilizadas foram transferidas para o meio Pierik (1976), com as vitaminas MS e sem reguladores de crescimento. Foram usados quatro tratamentos, todos em cultura líquida com ponte de papel-filtro, cada um com dez plântulas, no total de $\mathbf{4 0}$ plântulas por tratamento, conforme quadro 2.

Nos terceiro ensaio (III), retiraram-se as plântulas do meio de propagaçāo, transferindo-as para o Pierik (1976) com vitaminas do MS e sem reguladores de crescimento, e no qual permaneceram por 60 dias, com o objetivo de reduzir o efeito da citocinina 6-BA. $O$ ensaio constou de seis tratamentos, inoculando-se 40 plântulas de Rosa 'Shafter' por tratamento - Quadro 3. 
Quadro 1. Composição de meios, tipos de cultura e condições ambientais testados para micropropagação de Rosa 'Shafter' - Ensaio I

Tratamento Composição do meio Tipo de cultura Condições ambientais

1

3

4

5

6
2

Pierik (1976)

$0,3 \mathrm{mg} / \mathrm{l}$ tiamina

$50 \mathrm{~g} / 1$ sacarose

pH 5,8

$$
\begin{aligned}
& \text { Pierik (1976) } \\
& 0,3 \mathrm{mg} / 1 \text { tiamina } \\
& 0,075 \mathrm{mg} / 1 \text { AIB } \\
& 0,1 \mathrm{mg} / 1 \text { ANA } \\
& 50 \mathrm{~g} / 1 \text { sacarose } \\
& \text { pH } 5,8
\end{aligned}
$$

3 Idem ao anterior

Pierik (1976)

$0,3 \mathrm{mg} / 1$ tiamina

$0,033 \mathrm{mg} / 1$ AIB

$0,1 \mathrm{mg} / 1$ ANA

$50 \mathrm{~g} / 1$ sacarose

pH 5,8

5 Idem ao anterior

Idem ao anterior
Líquida com ponte

de papel-filtro

Idem ao tratamento 1

Idem ao tratamento 1

Sólida com $6,4 \mathrm{~g} / \mathrm{l}$ de ágar

Idem ao tratamento 4

Idem ao tratamento 4
700 lux 16 horas de fotoperíodo, $25 \pm 2^{\circ} \mathrm{C}$ de

temperatura

Idem ao tratamento 1
6 dias no escuro; depois: mesmo tratamento dos anteriores

Idem ao tratamento 1

Idem ao tratamento 3

A base do frasco sombreada, 300 lux (lâmpadas Gro-lux)

\subsection{Aclimatação das plântulas}

As plântulas enraizadas foram transferidas para aclimatação, em bandejas contendo vermiculita autoclavada, umedecida com macronutrientes do meio básico de MS, e vedadas com filme plástico. Como condições ambientes, mantiveram-se as do cultivo in vitro, onde as plântulas permaneceram por aproximadamente $\mathbf{4 5}$ dias; a seguir, foram transplantadas para recipientes plásticos individuais com um substrato suplementado com nutrientes, no qual ficaram cerca de 90 dias. Finalmente, foram transplantadas para sacos plásticos com terra e transferidas para casa de vegetação. 
Quadro 2. Composição de meios, tipos de cultura e condiçóes ambientais testados para micropropagação de Rosa 'Shafter' - Ensaio II

Tratamento Composição do meio

Pierik (1976)

$0,3 \mathrm{mg} / \mathrm{l}$ tiamina

$50 \mathrm{~g} / 1$ sacarose

pH 5,8

2

3

Pierik (1976)

$0,3 \mathrm{mg} / \mathrm{l}$ timanina

$0,05 \mathrm{mg} / 1$ AIB

$0,1 \mathrm{mg} / 1$ ANA

$50 \mathrm{~g} / 1$ sacarose

pH 5,8

4

Idem ao tratamento 3
Líquida com ponte de papel-filtro

Tipo de cultura

Condiçōes ambientais

7 dias no escuro; depois:

$700 \mathrm{lux}, 16$ horas de

fotoperíodo, $25 \pm 2^{\circ} \mathrm{C}$

de temperatura

Idem ao tratamento 1

Idem ao tratamento 1

700 lux, 16 horas de

fotoperíodo, $25 \pm 2{ }^{\circ} \mathrm{C}$

de temperatura

Idem ao tratamento 1

Quadro 3. Composição de meios, tipos de cultura e condiçōes ambientais testados para micropropagação de Rosa 'Shafter' - Ensaio III

Tratamento Composição do meio

Pierik (1976)

$0,3 \mathrm{mg} / \mathrm{l}$ tiamina

50 g/1 sacarose

pH 5,8

$2 \quad$ Pierik (1976)

$0,3 \mathrm{mg} / 1$ tiamina

$0,05 \mathrm{mg} / \mathrm{AIB}$

$0,1 \mathrm{mg} / \mathrm{l}$ ANA

$50 \mathrm{~g}$ sacarose

pH 5,8

Tipo de cultura

Condiçōes ambientais

Liquida com ponte de

papel-filtro

Idem ao tratamento 1
700 lux, 16 horas de fotoperíodo, $25 \pm 2^{\circ} \mathrm{C}$ de temperatura

Idem ao tratamento 1 


\begin{tabular}{cccl} 
Tratamento & Composição do meio & Tipo de cultura & Condiçóes ambientais \\
\hline 3 & Idem ao tratamento 2 & Idem ao tratamento 1 & $\begin{array}{l}9 \text { dias no escuro; depois: } \\
\text { mesmo tratamento dos } \\
\text { anteriores }\end{array}$ \\
4 & Idem ao tratamento 2 & Sólida com $6,4 \mathrm{~g} / 1$ de ágar & $\begin{array}{l}\text { Idem ao tratamento } 1 \\
5\end{array}$ \\
Idem ao tratamento 2 & Idem ao tratamento 4 & Idem ao tratamento 3 \\
6 & Idem ao tratamento 2 & Idem ao tratamento 4 & $\begin{array}{l}\text { A base do frasco sombre- } \\
\text { ada, 300lux (lâmpadas } \\
\text { Gro-lux) }\end{array}$
\end{tabular}

\section{RESULTADOS E DISCUSSĀO}

\subsection{Cultura de meristema}

Na relação abaixo, pode-se observar a evolução da cultura de meristemas inoculados em 16-5-89 do porta-enxerto 'Shafter'.

Evolução da quantidade de meristemas e plântulas cultivadas in vitro de Rosa 'Shafter' (PE-17)

Data Plântulas produzidas

1989:

16/5 33 meristemas inoculados (inicial).

15/8 9 plântulas regeneradas.

19/9 Transferidas para novo meio 21 plântulas.

4/12 Transferidas para novo meio 62 plântulas.

1990:

10/1 Transferidas para novo meio 100 plântulas. 8/5 Aproximadamente 1.000 plântulas obtidas.

Em um ano, aproximadamente, observou-se perfilhamento considerado grande, produzindo, a partir de 33 meristemas, acima de 1.000 plântulas. Em 18-7-90, foram retiradas 240 plântulas para o primeiro ensaio de enraizamento; em 18-10-90, mais 160 para o segundo e, quando as plântulas se encontravam com cerca de $4 \mathrm{~cm}$, efetuou-se o terceiro ensaio de enraizamento.

Em funçāo dos resultados, fica demonstrada a eficiência do método, confirmando o Pierik como meio básico para a micropropagaçāo dessa roseira. Esse resultado foi atingido depois de dois anos de testes de diversos processos descritos na bibliografia (Tombolato et al., 1988). O meio Pierik foi testado para outras variedades-copa e porta-enxertos de roseira, demonstrando ser aplicável para a maioria delas $\left({ }^{6}\right)$.

Na literatura especializada, são poucos os relatos, anteriores a este trabalho, de obtenção de rosa via meristema, sendo normalmente utilizados ápices com, às vezes, até $1 \mathrm{~cm}$ de comprimento. Este procedimento se torna de difícil aplicação para as condiçōes de cultivo adotado em nosso Estado, em razão de o material inicial ser proveniente de cultura de campo e extremamente contaminado por impurezas (Tombolato et al., 1988).

(6) Resultados não publicados - Relatório FAPESP, Processo n. $90 / 4923-2,1991$. 


\subsection{Ensaios de enraizamento}

Na figura 1, encontram-se os resultados de porcentagens de enraizamento obtidos no primeiro ensaio, ao final de 26 dias (em 13-8): entre os tratamentos do meio líquido, o melhor resultado foi obtido no tratamento $3(57,5 \%)$, seguido pelo 1 (55\%). Contudo, num período de 18 dias (em 6-8), o tratamento 1, com o meio de Pierik (1976) desprovido de auxina, apresentou uma porcentagem de enraizamento igual ao do tratamento $3(52,5 \%)$, constituído do mesmo meio acrescido de AIB e ANA.

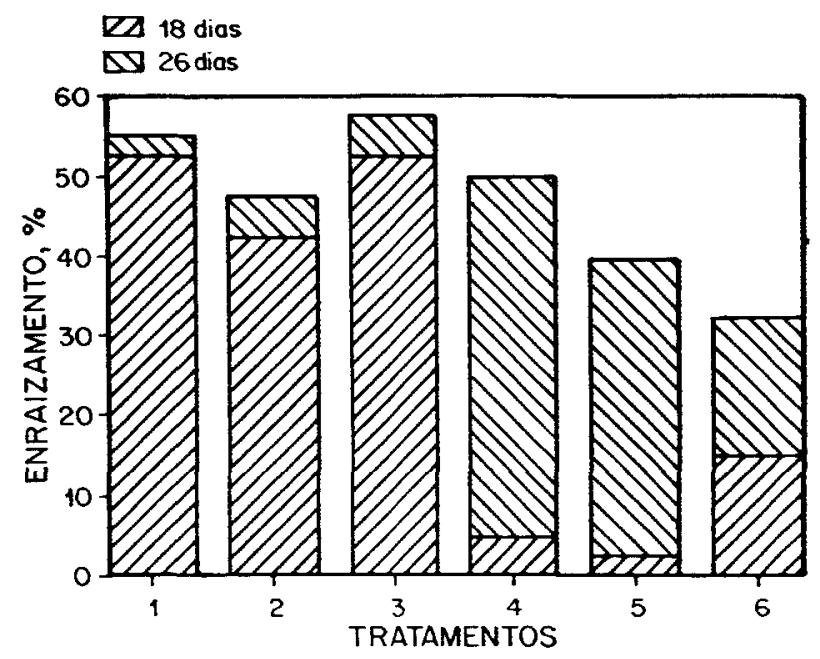

Figura 1. Porcentagem total de microestacas enraizadas de Rosa 'Shafter' obtidas em duas datas e tratamentos de enraizamento do ensaio I. Instituto Agronómico, 1991.

Os tratamentos 2, líquido, e 4, sólido, tiveram uma porcentagem de enraizamento final semelhante, apesar de que, nos primeiros 18 dias (em 6-8), o 2 apresentava $42 \%$ de enraizamento, enquanto o 4, apenas 5\%. O enraizamento mais tardio deve-se provavelmente ao ágar, vindo este a ser um obstáculo a ser vencido pelas raízes, fato já observado em testes preliminares. Nos tratamentos sólidos, apesar da menor quantidade de AIB, houve muita formação de calo e uma porcentagem de enraizamento muito baixa em relação aos líquidos. Os tratamentos 5 e 6 apresentaram excessiva formação de calo na base da estaca, o que se refletiu no baixo enraizamento.
Essa formação excessiva de calo pode ser atribuída à redução de auxina e à manutenção dos explantes em condições de luminosidade insuficiente.

Quando se compara o tipo de cultura, sólida ou líquida, pode-se constatar uma grande diferença. Nos tratamentos com cultura líquida, o enraizamento é mais rápido, há pouca formação de calo, porém as plântulas apresentam as folhas amareladas (cloróticas). Nos sólidos, as folhas são verdes, há muita formação de calo e poucas rázes. A solidez do meio representa, provavelmente, certa barreira a ser rompida pela raiz, acarretando um enraizamento mais tardio. Constatou-se, entretando, no meio sólido, a emissāo de raízes simultânea ao desenvolvimento da parte aérea.

O meio líquido favoreceu o aparecimento de pêlos absorventes devido à inexistência de obstáculos físicos, permitindo a aeração das raízes; contudo, as plântulas requerem rápida transferência para a prevençāo de perdas.

No ensaio II - Figura 2 - quando se comparam os tratamentos em cultura líquida com auxina (1 e 2) com os sem auxina (3 e 4), observam-se poucas diferenças. Sem auxina, o tratamento 2 , no claro, apresentou-se superior (95\%) ao 1 , no escuro (82,5\%). Com auxina, ao contrário, maior enraizamento foi observado no tratamento 3 , no escuro $(92,5 \%)$, em relação ao claro $(82,5 \%)$.

As plântulas dos tratamentos no escuro, ao final das avaliaçōes, apresentaram folhas mais amareladas e dessecadas, quando comparadas às dos tratamentos no claro. Dessa forma, no escuro, as plântulas tornaram-se fracas para posterior aclimatação, enquanto as do tratamento no claro permaneceram com folhas verdes.

No ensaio III, pôde-se observar enraizamento quase total na maioria dos tratamentos - Figura 3. Supôe-se que esse alto índice de enraizamento se deva ao tamanho original das plântulas (aproximadamente $4 \mathrm{~cm}$ de altura) e ao processo de retirada do efeito da citocinina (6-BA), pelo cultivo prévio em meio Pierik (1976) com vitaminas do MS e sem reguladores de crescimento por 60 dias. Pode-se verificar que houve maior diferença na porcentagem 
de. enraizamento dos primeiros 16 dias (até 2-1) em relação aos tratamentos sólido e líquido. Como já mencionado no ensaio I, pressupōe-se que essa diferença se deva à barreira que as raízes encontram com relação ao ágar.

No tratamento 5 , cujos resultados foram bem diferentes dos demais, houve excessiva formação de calo, além de muitas plântulas morrerem por contaminação, acarretando resultados insatisfatórios, com 42,5\% das plântulas não enraizando.

Nos tratamentos líquidos, obtiveram-se novamente plântulas com folhas cloróticas e secas. Isso revela que esses tratamentos, apesar de propiciarem um enraizamento mais rápido, acarretam a formação de plântulas menos vigorosas.

\section{Comparação dos resultados dos ensaios de en- raizamento}

Nos diferentes ensaios de enraizamento, nos tratamentos em que se utilizou o meio líquido com ponte de papel-filtro, com auxina e no claro, as plântulas apresentaram enraizamento mais rápido. Nessas condiçōes, as plântulas com aproximadamente $\mathbf{4} \mathrm{cm}$ enraizaram mais facilmente que aquelas menores. Quando se aplicou o mesmo tratamento, sem auxina na composição do meio, a porcentagem de enraizamento não foi a melhor, mas suas folhas se apresentaram mais verdes e a taxa de sobrevivência na fase de aclimataçáo, mais elevada.

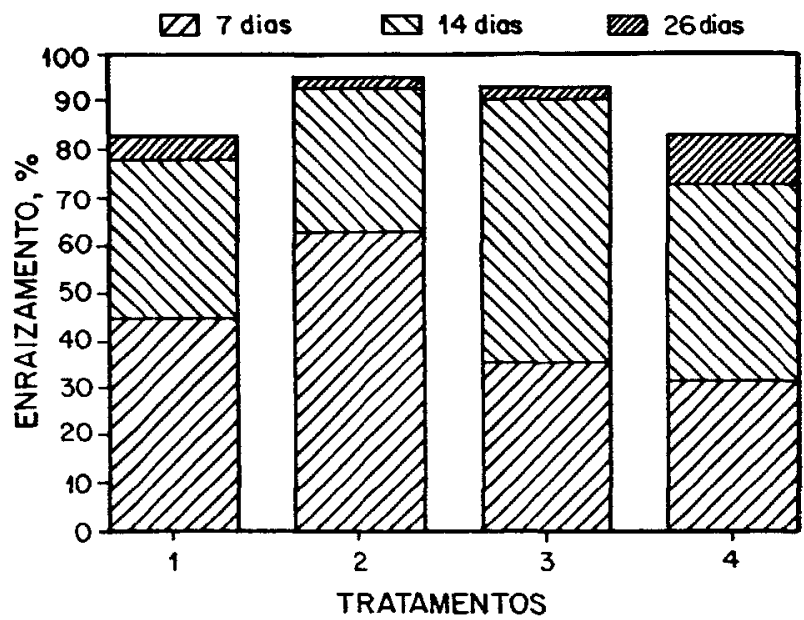

Figura 2. Porcentagem total de microestacas enraizadas de Rose 'Shafter' obtidas em diferentes tratamentos de enraizamento do ensaio II.

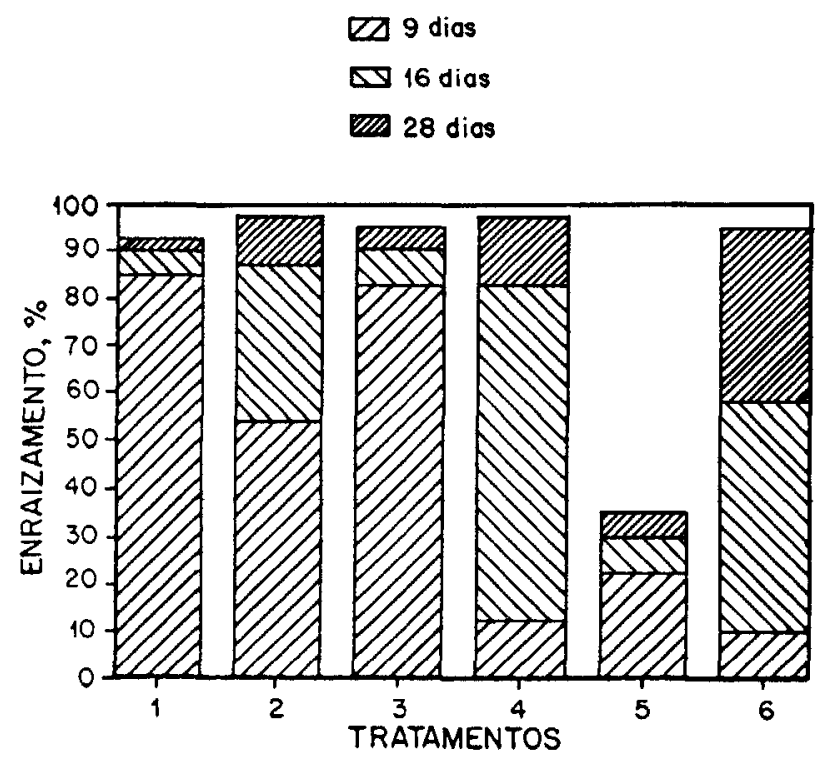

Figura 3. Porcentagem total de microestacas enraizadas de Rosa 'Shafter' obtidas em diferentes tratamentos de enraizamento do ensaio III. Instituto Agronómico, 1991.

As plântulas dos tratamentos em meio sólido mantiveram as folhas verdes durante a fase de enraizamento. Este, no entanto, foi mais demorado, pois a solidez do meio parece representar uma barreira a ser rompida pelas raízes. Nesse meio, notou-se também elevada ocorrência de formação de calo, provavelmente devido ao excesso de auxina, uma vez que as plântulas permanecem em contato direto com um meio rico em auxinas (AIB). Não houve dessecamento de plantas.

Apesar de os tratamentos em meio líquido terem apresentado um enraizamento mais rápido, independentemente da presença ou da ausência de auxina, as plântulas mostraram um aspecto inferior ao daquelas que se encontravam nos tratamentos sólidos. Com a utilização de meio líquido, requer-se, provavelmente, uma transferência mais rápida das plântulas para aclimatação, evitando seu enfraquecimento durante essa fase de indução ao enraizamento.

Pela análise dos resultados, observa-se que quando as plântulas permanecem no escuro ou em baixa luminosidade, a formação de calo e maior, em detrimento da formação de raízes. 


\section{CONCLUSÃo}

A cultura in vitro de meristemas de Rosa 'Shafter' pode ser realizada com bastante eficiência pelo método descrito, com o meio de Pierik (1976) suplementado com os compostos orgânicos relacionados no método.

O enraizamento pode ser obtido em duas semanas, em meio líquido, com ou sem auxina, sobre ponte de papel-filtro, ou em um mês, em meio sólido, com as auxinas AIB $0,05 \mathrm{mg} / \mathrm{l}$ e ANA $0,1 \mathrm{mg} / 1$. Para plântulas com mais de $4 \mathrm{~cm}$ de altura, a fase de enraizamento não apresenta dificuldades maiores, desde que se observem os aspectos de assepsia e se evite o excesso de auxinas nas condiçōes de enraizamento.

\section{AGRADECIMENTO}

À Técnica de Laboratório da Seçāo de Floricultura e Plantas Ornamentais, Ana Maria Molini Costa, cuja dedicaçāo contribuiu para o eficiente atendimento das etapas do presente trabalho.

\section{REFERENCIAS BIBLIOGRÁFICAS}

BARBOSA, W.; CAMPO-DALL'ORTO, F.A.; OJIMA, M.; CAMPOS, S.A.F. de \& TOMBOLATO, A.F.C. Propagaçăo vegetativa in vitro de cultivares de macieira. Bragantia, Campinas, 45(1):143-154, 1986.

BUTTERFIELD, H.M. Rose culture in California. Berkeley, University of California, 1950. 41p. (Circular 148)

DECKER, J.S. \& MENDES, F.A.T. Rosas, dahlias e gladiolos. Boletim de Agricultura, Săo Paulo, 40:440-532, 1939.

GAULT, S.M. \& SYNGE, P.M. The dictionary of roses. 2.ed. London, Rainbird Publishing, 1987. 191p.

LOPES, L.C. A cultura da roseira. Viçosa, Universidade Federal de Viçasa, 1980. 21p. (Boletim de Extensão, 3)

MURASHIGE, T. \& SKOOG, F. A revised medium for rapid growth and bio assays with tabacco tissue cultures. Physlologla Plantarum, Copenhagen, 15(3):473-497, 1962.

PIERIK, R.LM. Anthurium andraeanum plantlets produced from callus tissues cultivated in vitro. Physiologia Plantarum, Copenhagen, 37(1):80-82, 1976.

SKIRVIN, RM. \& CHU, M.C. In vitro propagation of 'Forever Yours' rose. HortScience, Alexandria, 14(5):608-610, 1979.

TOMBOLATO, A.F.C.; TAKEBAYASHI, S.S.G. \& CASTRO, C.E.F. de. A pesquisa mundial e nacional na micropropagaçáo da roseira. O Agronômico, Campinas, 40(3):209-219, 1988. 